\title{
GLK-8903 Reduces Membrane Phospholipid Peroxidation and Alleviates Chilling Injury in Phaseolus vulgaris $\mathbf{L}$.
}

\author{
Cheng-lie Zhang and Paul H. Li \\ Laboratory of Plant Hardiness, Department of Horticultural Science, University of Minnesota, St. Paul, \\ MN 55108 \\ Charles C. Shin ${ }^{1}$ \\ Great Lakes Chemical Corporation, West Lafayette, IN 47906
}

Additional index words. antioxidation, catalase, common bean, hydrogen peroxide, malondialdehyde, peroxidase, superoxide dismutase

\begin{abstract}
Twenty-day-old 'Bush Blue Lake 47' common bean plants grown in a growth chamber at 25 days/22C night and a 12-hour photoperiod regime were foliar sprayed with $0.5 \%$ GLK-8903 including $0.05 \%$ Tween-20. After 24 hours of treatment, plants were chilled in a cold room (4C day/night, 12 hours of light). After 3 days of chilling, leaves of untreated controls were injured, as visually characterized by leaf wilting, whereas leaves of the GLK-8903-treated plants still retained turgor. During chilling, the activity of superoxide dismutase (SOD), peroxidase (POD), and catalase (CAT) decreased. GLK-8903 treatment had no effect on SOD and POD activities; however, the CAT activity was reduced significantly after GLK-8903 treatment either at 25 or at 4C. During chilling, the content of malondialdehyde, a decomposition product of phospholipid peroxidation, increased in treated plants and untreated controls, with increased content significantly lower in the former compared with the latter. The GLK-8903 per se and total lipid extracted from GLK-8903-treated plants were able to reduce the linoleic acid oxidation in vitro. The mechanism by which GLK-8903 alleviates chilling injury in bean plants is discussed.
\end{abstract}

Flores-Nimedez et al. (1993) reported that GLK-8903 alleviated chilling injury in common bean plants by reducing the plasma membrane perturbation in a chilling environment. Levitt (1980) has suggested that plants survive low-temperature stress by tolerance, avoidance, or both. Exogenously applied abscisic acid (ABA) alleviates maize cells from chilling injury (Xin and $\mathrm{Li}, 1992$ ). However, tolerance was not increased when cells were exposed to chilling at the inception of ABA treatment. A minimum of $6 \mathrm{~h}$ of $\mathrm{ABA}$ treatment at the warm temperature is required (Xin and $\mathrm{Li}$, 1992). The alleviation of chilling injury in this case is believed to be through the mechanism of ABA-induced tolerance. Unpublished work in our laboratory has shown that bean plants can be protected from chilling injury immediately after the application of GLK-8903, most likely due to the stress avoidance.

Several studies have shown that, during chilling, plant membrane damage is related to the peroxidation of membrane lipids due to the stress-induced accumulation of free radicals (Clare et al., 1984; Kaniuga et al., 1978; Michalski and Kaniuga, 1981, 1982; Powles, 1984; Wise and Naylor, 1987). We, therefore, examined 1) the effect of GLK-8903 on the activity of superoxide dismutase, peroxidase, and catalase, the enzymes responsible for scavenging peroxide anion $\left(\mathrm{O}_{2}^{-}\right)$and $\left.\mathrm{H}_{2} \mathrm{O}_{2} ; 2\right)$ the potential of GLK-8903 in reducing the oxidation of unsaturated fatty acids in vitro; and 3 ) the antioxidation potential of the total lipids extracted from the GLK-8903-treated plants. We hypothesized that the mode of action of GLK-8903 is through the prevention of the peroxidation of the membrane lipids.

Received for publication 16 Mar. 1993. Accepted for publication 10 June 1993 Scientific journal series paper no. 20526 of the Minnesota Agricultural Experiment Station, St. Paul. This research was supported in part by a gift from Great Lakes Chemical Corp. We thank David W. Davis for his critical reading of the manuscript. The cost of publishing this paper was defrayed in part by the payment of page charges. Under postal regulations, this paper therefore must be hereby marked advertisement solely to indicate this fact.

${ }^{1}$ To whom requests for GLK-8903 information should be addressed.

\section{Materials and Methods}

Plant material and treatments. 'Bush Blue Lake 47' (BBL 47) (Asgrow, Kalamazoo, Mich.) common bean seeds were sown in a mix containing 2 peat : 1 soil : 1 sand (by volume) in $15-\mathrm{cm}-$ diameter pots. Seedlings were thinned to two per pot and raised in a growth chamber at a regime of 25 days/22C nights and a 14-h photoperiod with a photon flux density of $300 \mu \mathrm{mol} \cdot \mathrm{m}^{-2} \cdot \mathrm{s}^{-1}$. When plants were $\approx 20$ days old, they were sprayed with $0.5 \%$ GLK- 8903 containing $0.05 \%$ Tween- 20 until the leaves were completely wet. Plants sprayed with water containing $0.05 \%$ Tween-20 served as the control.

Twenty-four hours after spraying, plants were transferred to a cold room at $4 \mathrm{C}$ and a $14 \mathrm{~h}$-photoperiod with a photon flux density of $45 \mu \mathrm{mol} \cdot \mathrm{m}^{-2} \cdot \mathrm{s}^{-1}$. Plants were chilled for 1,2 , or 3 days. Plants were watered during chilling. At the end of each chilling period (after day 1,2, or 3), plants were removed from the cold room to the growth chamber for recovery observation. The first set of samples was collected immediately after foliar spraying. The second set of samples was collected $24 \mathrm{~h}$ after spraying, just before transfer to the cold room. The third, fourth, or fifth sets of samples were collected after 1, 2, or 3 days of chilling, respectively. The sixth set of samples was collected after 3 days of recovery at 25/ $22 \mathrm{C}$.

$G L K-8903$. GLK-8903 is an experimental product of the Great Lakes Chemical Corp., West Lafayette, Ind. Its main active ingredient is produced by the hydrogenation of a primary alcohol extracted from plants. It is a colorless, high-boiling-point primary alcohol containing a heterocyclic ring. Due to its cyclic ether and alcohol structure, it has some unique solvent properties, such as low volatility, easy absorbability, high membrane penetrability, limitless solubility in water in addition to its ability to form multiple hydrogen bonds, and ability to dissolve electrolyte and nonelectrolyte solutes.

Determination of superoxide dismutase (SOD, EC 1.15.1.1) 
and peroxidase (POD, EC 1.11.1.7) activities. The first trifoliate leaf was harvested from about seven to eight plants. One-half g tissue of the first trifoliate leaves was weighed and homogenized in a mortar and pestle at ice-cold temperature with $5 \mathrm{ml}$ of $50 \mathrm{~mm}$ phosphate buffer ( $\mathrm{pH} 7.8$ ) containing $10 \mathrm{~mm}$ mercaptoethanol and $1 \%$ polyvinylpyrrolidone. The homogenate was centrifuged at $15,000 \times g$ for $10 \mathrm{~min}$, and the supernatant was saved and used as an enzyme source for the determinations of SOD and POD activities.

SOD activity was assayed according to the method of Beauchamp and Fridovich (1971) as modified by Oberley and Spitz (1985). Total activity was determined by inhibiting the reduction of tetrazolium blue by the superoxide radicals generated by the xanthine-xanthine oxidase system. One unit of SOD was defined as the amount of the supernatant that yielded a $50 \%$ inhibition of the reduction of tetrazolium blue.

POD activity was assayed according to the method of Putter (1974), with one unit defined as the amount of the supernatant resulting in an $\mathrm{OD}_{470}$ increase of $0.1 / \mathrm{min}$.

Determination of catalase (CAT, EC 1.11.1.6.) activity. Onehalf gram of tissue of the first trifoliolate leaves was weighed and homogenized in a mortar and pestle at ice-cold temperature with 5 $\mathrm{ml}$ of $50 \mathrm{~mm}$ phosphate buffer ( $\mathrm{pH} 7.0$ ), and the homogenate was centrifuged at $10,000 \times g$ for $10 \mathrm{~min}$. Cold acetone was added to the supernatant to a final concentration of $80 \%$. After mixing and centrifugation $(3000 \times g$ for $10 \mathrm{~min})$, the precipitate was saved and dissolved with $5 \mathrm{ml}$ of $50 \mathrm{~mm}$ phosphate buffer ( $\mathrm{pH} 7.0)$. This preparation served as CAT source. CAT activity was determined by measuring the time required for a decrease in absorbance at 240 nm from 0.450 to 0.400 (Aebi, 1983).

Determination of protein content. Protein content was determined according to the method of Layne (1957), with bovine albumin as the reference.

Measurement of malondialdehyde (MDA) content. MDA is a decomposition product of lipid peroxidation. The MDA content was determined by the reaction of thiobarbituric acid (TBA), as described by Dhindsa et al. (1982). One-half gram of trifoliolate tissue was homogenized in $5 \mathrm{ml}$ of $0.1 \%$ trichloroacetic acid (TCA). The homogenate was centrifuged at $10,000 \times g$ for $5 \mathrm{~min}$. To $1 \mathrm{ml}$ of supernatant, $2 \mathrm{ml}$ of $4 \%$ TCA containing $0.5 \%$ TBA was added. The mixture was heated at $95 \mathrm{C}$ for $30 \mathrm{~min}$, then cooled down to room temperature and centrifuged at $10,000 \times g$ for $10 \mathrm{~min}$. The OD value of the supernatant was measured at 532 and $600 \mathrm{~nm}$. The MDA content was calculated according to the molar extinction coefficient of the MDA $\left(155 \mu \mathrm{M} \cdot \operatorname{liter}^{-1} \cdot \mathrm{cm}^{-1}\right)$.

Measurement of $\mathrm{H}_{2} \mathrm{O}_{2}$ content. One gram of tissue of the first trifoliolate leaves was weighed and homogenized in $5 \mathrm{ml}$ of cold acetone. The homogenate was centrifuged at $1250 \times g$ for $10 \mathrm{~min}$, and then $0.1 \mathrm{ml}$ of titanium chloride $(20 \%$ in concentration $\mathrm{HCl}$ ) was added to the supernatant. While the solution was shaking, a 3.5-ml aliquot of one-fifth strength $\mathrm{NH}_{4} \mathrm{OH}$ was added dropwise with thorough mixing, with further centrifugation at $1250 \times g$ for 5 min. The precipitate was washed repeatedly with $5 \mathrm{ml}$ of acetone each time until the supernatant became colorless. The precipitate was solubilized in $10 \mathrm{ml}$ of $2 \mathrm{~N} \mathrm{H}_{2} \mathrm{SO}_{4}$ and filtered before absorbance was measured at $415 \mathrm{~nm}$ against a blank that had been prepared similarly without plant sample. The $\mathrm{H}_{2} \mathrm{O}_{2}$ concentration was determined by comparing a standard reference representing the titanium- $\mathrm{H}_{2} \mathrm{O}_{2}$ complex from a range of 0.1 to $1 \mathrm{~mm}$ (Patterson et al., 1984).

Measurements of the antioxidation potential of GLK-8903 and the total lipids extracted from GLK-8903-treated plants. Total lipids (per sample) were extracted from $1 \mathrm{~g}$ tissue of the first trifoliolate leaves in $10 \mathrm{ml}$ of 2 cold chloroform : 1 methanol with a polytron homogenizer in a $4 \mathrm{C}$ cold room. After centrifugation, the supernatant was partitioned with an equal volume of $0.7 \%$ $\mathrm{NaCl}$. The organic phase was saved and evaporated to dryness, resuspended in $1 \mathrm{ml}$ of ethanol, and stored at $-20 \mathrm{C}$ under $\mathrm{N}$ (Kendall and McKersie, 1989). All samples were adjusted with ethanol to a similar lipid concentration. The antioxidation potential of the total lipids or GLK-8903 per se was determined by monitoring the inhibition of linoleic acid oxidation as described by Senaratna et al. (1985). An emulsion was formed by mixing $0.2 \mathrm{ml}$ of $0.2 \mathrm{M}$ linoleic acid with $0.1 \mathrm{ml}$ of sample extract, GLK-8903, 2tocopherol (standard), or ethanol alone (control), and to which $3 \mathrm{ml}$ of $10 \mathrm{~mm} \mathrm{KH} \mathrm{PO}_{4}(\mathrm{pH} 6.8)$ was added. The reaction was initiated by adding $1.5 \mathrm{ml}$ of $0.2 \mathrm{~mm} \mathrm{FeSO}_{4}$-EDTA at $37 \mathrm{C}$. An aliquot of the emulsion was monitored by measuring the absorbance at $232 \mathrm{~nm}$. Percent inhibition of oxidation was calculated as $\left[\left(\mathrm{OD}_{232}\right.\right.$ of control - $\mathrm{OD}_{232}$ of sample)/OD ${ }_{232}$ of control]100. A standard curve for percentage inhibition by 2-tocopherol was constructed, and the relative quantity of the antioxidation potential of the sample extract, or of GLK-8903, was calculated from the standard curve as tocopherol equivalents.

\section{Results}

Alleviation of chilling injury in bean plants. Flores-Nimedez et al. (1993) reported that exposure of bean plants to 4C led to the development of chilling injury, visually characterized by leaf wilting. Plants sprayed with GLK-8903 retained leaf turgor during chilling. In the present study, we observed a similar phenomenon in which the leaf blades of untreated control plants were severely dried, whereas GLK-8903 reduced the chilling injury (Fig. 1) by preventing plants from wilting.

SOD activity. SOD activity decreased in both groups of plants during chilling $(4 \mathrm{C})$ and increased while recovering at $25 \mathrm{C}$ (Fig. 2 ). It has been reported that SOD decreases activity in response to chilling temperature (Chen and Patterson, 1988; Jahnke et al., 1991). Apparently, GLK-8903 treatment did not affect SOD activity either at 25 or at $4 \mathrm{C}$.

$P O D$ activity. POD activity declined significantly in untreated controls and the GLK-8903-treated plants during exposure to 4C (Fig. 3). After a 3-day recovery at 25C, POD activity in both groups of plants still remained at the low levels comparable to that found immediately after a 3-day chilling period. Again, GLK-8903

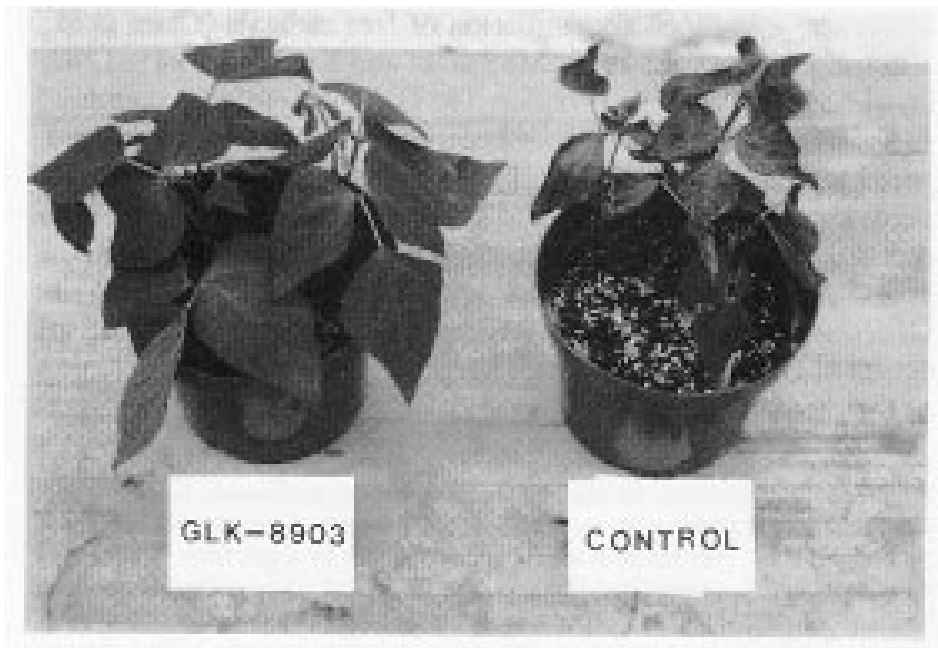

Fig. 1. Appearance of the GLK-8903-treated plants and untreated controls after 3 days at $4 \mathrm{C}$ and 1 day at $25 \mathrm{C}$. 


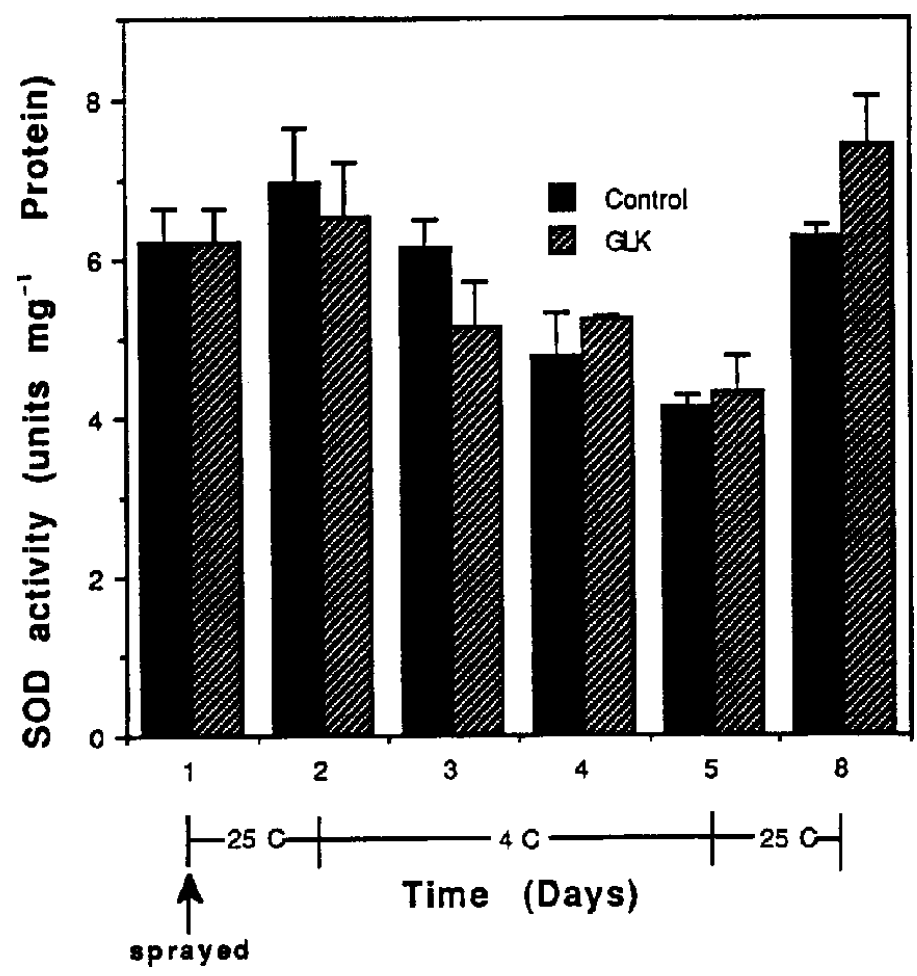

Fig. 2. Influence of GLK-8903 treatment on the activity of superoxide dismutase in bean leaves at 25 and $4 \mathrm{C}$.

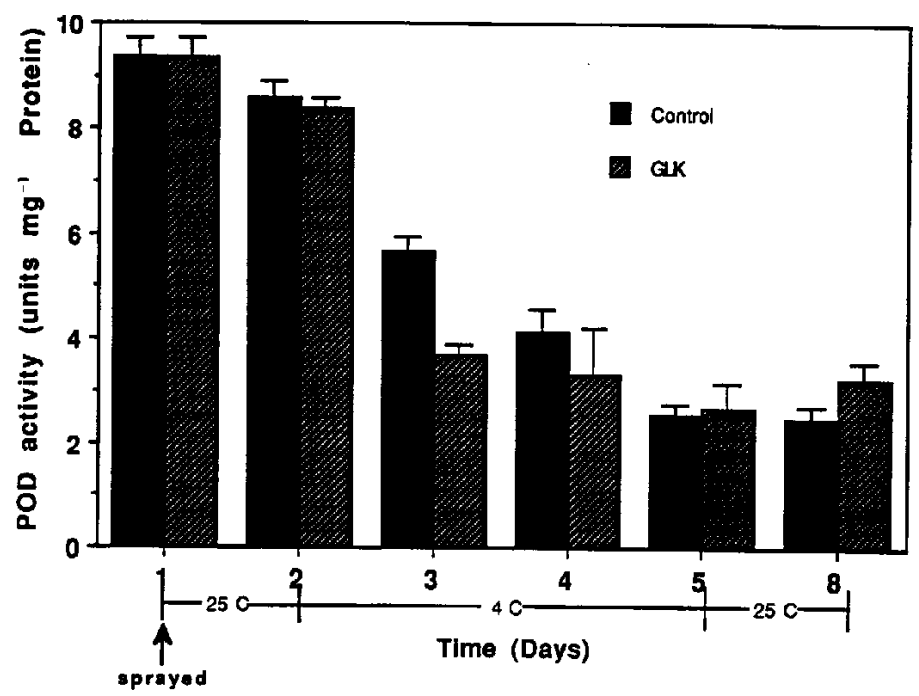

Fig. 3. Influence of GLK- 8903 treatment on the activity of peroxidase in bean leaves at 25 and $4 \mathrm{C}$.

treatment had no significant effect on POD activity either at $25 \mathrm{C}$ or at $4 \mathrm{C}$.

CAT activity. During chilling, CAT activity in untreated controls was progressively lower and recovered somewhat at $25 \mathrm{C}$ (Fig. 4). There was a drastic decrease in CAT activity after GLK-8903 treatment at 25 and 4C. Activity recovered somewhat in both groups of plants after exposure to $25 \mathrm{C}$ for 3 days. It seemed that the effectiveness of GLK-8903 on CAT activity had been dissipated to an insignificant level during the recovery. Thus, CAT activity increased to a level similar to that found in control plants.

$\mathrm{H}_{2} \mathrm{O}_{2}$ and $\mathrm{MDA}$ contents. The $\mathrm{H}_{2} \mathrm{O}_{2}$ content significantly increased during chilling in untreated controls and GLK-8903-treated plants, with the increase similar in both groups (Fig. 5). When

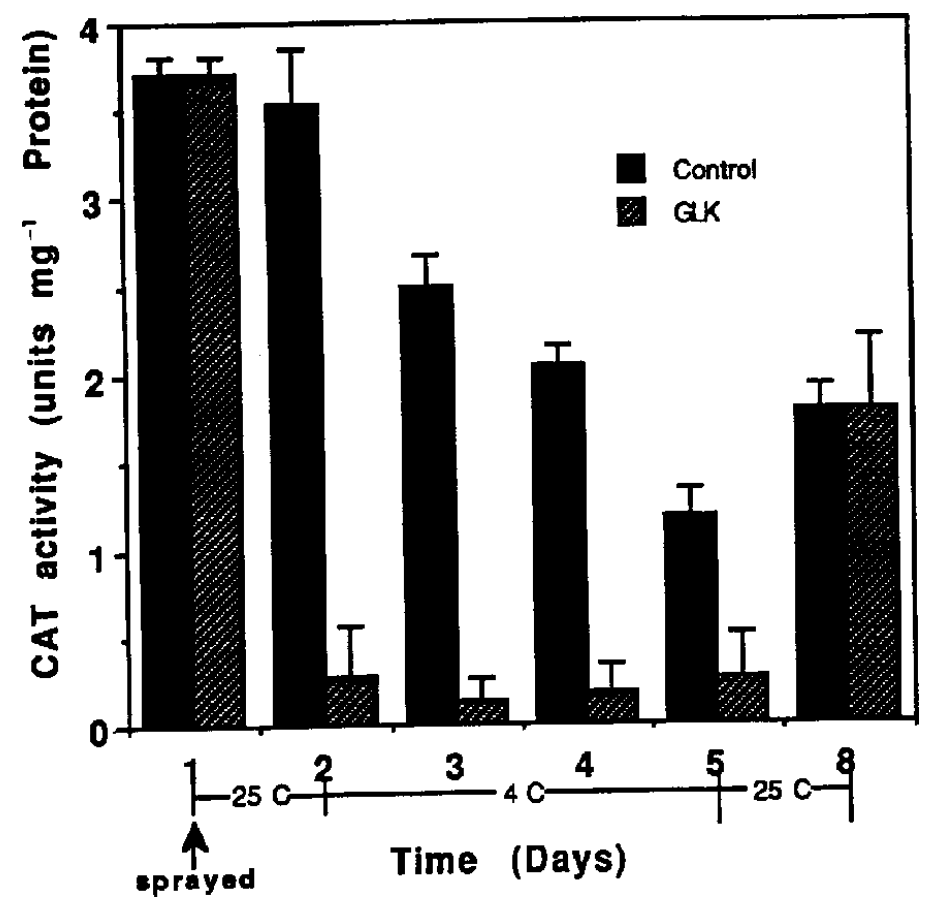

Fig. 4. Influence of GLK-8903 treatment on the activity of catalase in bean leaves at 25 and $4 \mathrm{C}$.

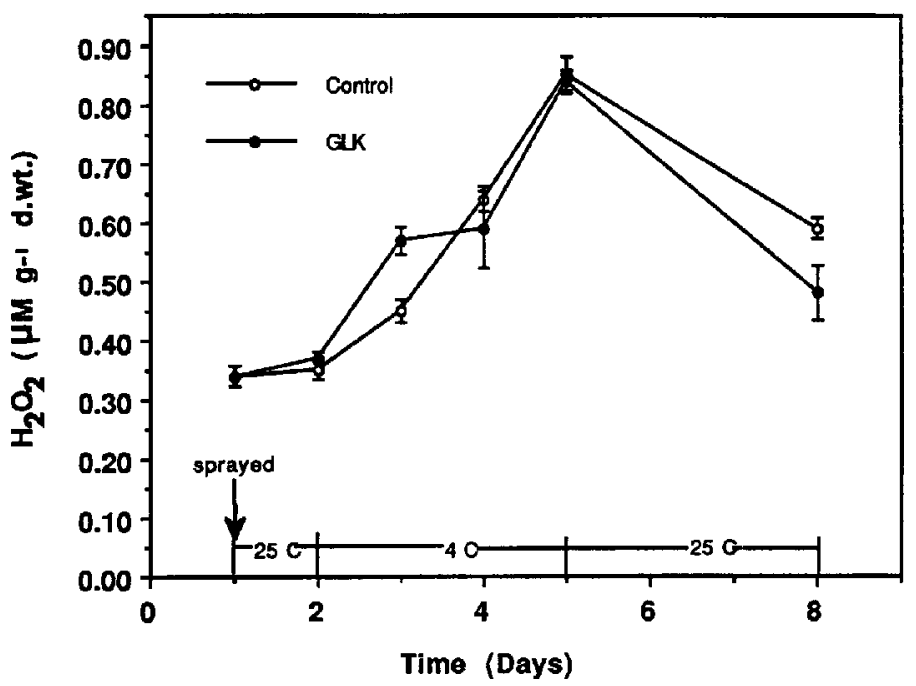

Fig. 5. The content of $\mathrm{H}_{2} \mathrm{O}_{2}$ in GLK-8903 treated and untreated bean leaves at 25 and $4 \mathrm{C}$.

chilled plants recovered at $25 \mathrm{C}, \mathrm{H}_{2} \mathrm{O}_{2}$ content decreased immediately.

MDA content increased immediately in the untreated controls when plants were exposed to $4 \mathrm{C}$ (Fig. 6) and continued to increase with prolonged chilling. During a 3-day recovery at 25C, MDA content still continued to increase. GLK-8903 treatment had no effect on the MDA content at 25C compared to the control. No increase in MDA content of the treated plants was observed after a 1-day chilling. The content increased after a 2-day chilling and continued to increase after a 3-day exposure. However, the increased content was significantly lower than that in the control. MDA also increased in the treated plants during the $25 \mathrm{C}$ recovery, with lower content than in the control.

Antioxidation potential of GLK-8903 and the total lipids. Alleviation of chilling injury can be seen when plants are exposed to 


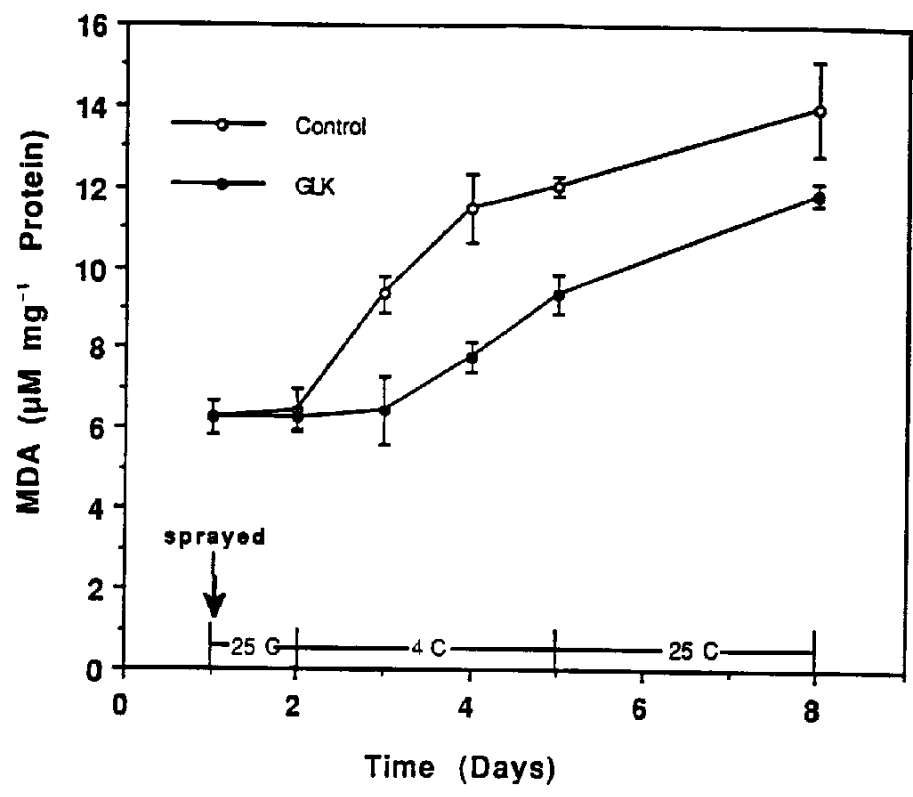

Fig. 6. The content of malondialdehyde in GLK-8903 treated and untreated bean leaves at 25 and $4 \mathrm{C}$.

chilling immediately after GLK-8903 application (Data not shown). The response differs from the ABA-induced chilling tolerance in maize cultured cells in which no increased tolerance is observed if chilling occurs at the inception of ABA treatment (Xin and $\mathrm{Li}$, 1992). This rapid effectiveness of GLK-8903 suggests to us the need to examine whether GLK-8903 per se is an antioxidizing agent. We observed that GLK-8903 inhibited the oxidation of linoleic acid in vitro. The higher the concentration of GLK-8903, the greater observed antioxidation of linoleic acid (Table 1). At 5\% and $0.5 \%$ concentrations of GLK-8903, there was $34 \%$ and $14 \%$ inhibition of linoleic acid from the oxidation, respectively, equivalent to 1.02 and $0.42 \mu \mathrm{g}$ of tocopherol $/ \mathrm{ml}$.

Total lipids extracted from 1-day GLK-8903-treated plants grown at $25 \mathrm{C}$ had a significantly greater capacity to inhibit the oxidation of linoleic acid than those from the untreated controls (Table 2) $-1.11 \mu \mathrm{g}$ of tocopherol $/ \mathrm{ml}$ vs. $0.7 \mu \mathrm{g} \cdot \mathrm{ml}^{-1}$ in the controls. After a 3-day growth at $25 \mathrm{C}$, the antioxidation potential of the total lipids in both groups of plants was essentially the same. Total lipids extracted from plants after 1-day and 2-day GLK-8903 treatments and grown at $4 \mathrm{C}$ also showed greater antioxidation potential than that of chilled, untreated controls. After a 3-day chilling, there was no difference in the inhibition of linoleic acid from the oxidation by the total lipids extracted from both groups of plants.

\section{Discussion}

Plants produce the superoxide radical $\left(\mathrm{O}_{2}^{-}\right)$via enzymatic or photochemical reactions. Hydrogen peroxide arises from either the dismutation of $\mathrm{O}_{2}^{-}$or from two consecutive monovalent reduction of oxygen (Gross et al., 1977). The hydroxyl radical $(\mathrm{OH} \cdot)$ is produced via electron transfer from $\mathrm{Fe}^{+2}$ to $\mathrm{H}_{2} \mathrm{O}_{2}$ (Porter and Wujek, 1988; Takahama and Nishimura, 1975). These highly reactive intermediates are responsible for the toxic character of $\mathrm{O}_{2}$. These free radicals can subtract $\mathrm{H}$ atoms from unsaturated fatty acids, resulting in the fatty radical (L.) (an initial phase of lipid peroxidation) (Asada and Takahashi, 1987). Molecular $\mathrm{O}_{2}$ adds to the fatty radical, resulting in the LOO radical (Slater and Cheeseman, 1988). The LOO radical can subtract $\mathrm{H}$ atoms from unsaturated fatty acids, forming $\mathrm{LOOH} \cdot$, thus propagating the
Table 1. The potential of GLK-8903 in reducing linoleic acid oxidation. Readings were taken $60 \mathrm{~min}$ after the initiation of the reaction. Data are means of five replications.

\begin{tabular}{lcc}
\hline \hline $\begin{array}{l}\text { GLK-8903 } \\
\text { concn } \\
(\%)\end{array}$ & $\begin{array}{c}\text { Reduction of } \\
\text { linoleic acid } \\
\text { oxidation }(\%)\end{array}$ & $\begin{array}{c}\text { Tocopherol } \\
\text { equivalent } \\
\left(\mu \mathrm{g} \cdot \mathrm{ml}^{-1}\right)\end{array}$ \\
\hline 10 & $33.7 \pm 0.42$ & 1.02 \\
5 & $33.6 \pm 3.76$ & 1.02 \\
1 & $23.2 \pm 5.30$ & 0.70 \\
0.5 & $13.7 \pm 5.59$ & 0.42
\end{tabular}

Table 2. Antioxidation potential of the total lipid obtained from the leaves of GLK-8903-treated bean plants. Data are means of four replications.

\begin{tabular}{|c|c|c|c|c|}
\hline \multirow[b]{2}{*}{ Treatment } & \multicolumn{2}{|c|}{$\begin{array}{c}\text { Duration } \\
\text { (days) }\end{array}$} & \multirow{2}{*}{$\begin{array}{l}\text { Reduction of } \\
\text { linoleic acid } \\
\text { oxidation }(\%)\end{array}$} & \multirow{2}{*}{$\begin{array}{c}\text { Tocopherol } \\
\text { equivalent } \\
\left(\mu \mathrm{g} \cdot \mathrm{ml}^{-1}\right)\end{array}$} \\
\hline & $25 \mathrm{C}$ & $4 \mathrm{C}$ & & \\
\hline Control $^{z}$ & 1 & --- & $24.95 \pm 0.83$ & 0.70 \\
\hline GLK-8903 & 1 & --- & $36.41 \pm 2.34^{* * *}$ & 1.11 \\
\hline Control & 3 & --- & $23.44 \pm 0.34$ & 0.71 \\
\hline GLK-8903 & 3 & --- & $22.64 \pm 0.16^{\mathrm{NS}}$ & 0.68 \\
\hline Control & 1 & 1 & $23.80 \pm 0.17$ & 0.70 \\
\hline GLK-8903 & 1 & 1 & $29.12 \pm 0.60^{* * *}$ & 0.88 \\
\hline Control & 1 & 2 & $26.49 \pm 0.52$ & 0.81 \\
\hline GLK-8903 & 1 & 2 & $28.13 \pm 0.16^{*}$ & 0.85 \\
\hline Control & 1 & 3 & $24.96 \pm 0.71$ & 0.76 \\
\hline GLK-8903 & 1 & 3 & $25.03 \pm 0.86^{\mathrm{NS}}$ & 0.76 \\
\hline
\end{tabular}

ZPlants sprayed with $\mathrm{H}_{2} \mathrm{O}$ including $0.05 \%$ Tween-20.

yPlants sprayed with $0.5 \%$ GLK-8903 including $0.05 \%$ Tween- 20 .

Ns,**** Nonsignificant or significant at $P \leq 0.05$ or 0.01 , respectively.

peroxidation of membrane lipids (a propagation phase of lipid peroxidation) (Asada and Takahashi, 1987). It can also subtract $\mathrm{H}$ atoms from proteins, forming a protein radical $(\mathrm{p} \cdot)$. Protein radicals can react additively to form a protein polymer $[\mathrm{P}(\mathrm{P}) \mathrm{aP} \cdot]$ (Elstner, 1982; Liu et al., 1985; Pryor, 1978). In addition, lipid peroxides can decompose to give off aldehydes, such as MDA (Halliwell, 1987). MDA can combine with the protein causing protein molecules to link into a conjugated form (Liu et al., 1985). Hence, MDA content can be taken as an index of the peroxidation level of the membrane lipids (Ohkawa et al., 1979; Symons et al., 1988). A series of free radical reactions, as described above, induces the denaturation of cellular membranes and the loss of membrane semipermeability, resulting in injury or ultimately death of the cells (Elstner, 1982; Senaratna et al., 1985; Takahama and Nishimura, 1975).

Under nonstress condition, plants can overcome the toxicity of superoxide and hydroxyl radicals by such antioxidizing agents as glutathione, ascorbate, and 2-tocopherol, as well as by enzymes such as superoxide dismutase, which converts the superoxide anion to $\mathrm{H}_{2} \mathrm{O}_{2}$, and lastly catalase and peroxidase, which scavenge the accumulated $\mathrm{H}_{2} \mathrm{O}_{2}$ to a nontoxic level (Cadenas, 1989).

Bean plants displayed an obvious chilling injury as characterized by leaf wilting (Fig. 1). Chilling also reduced SOD, POD, and CAT activity. The longer the period of chilling, the greater the enzyme activity decreased (Figs. 2-4). Consequently, the $\mathrm{H}_{2} \mathrm{O}_{2}$ and MDA contents increased markedly (Figs. 5 and 6). We believe that the chilling-induced injury in bean plants involves at least partially the peroxidation of membrane lipids, as evident by the swelling of protoplasts and the increased plasma membrane permeability coefficient to urea (Flores-Nimedez et al., 1993). FloresNimedez et al. (1993) also showed that the increased electrolyte 
leakage was significantly reduced in the GLK-8903-treated plants during chilling (4C), an indication that GLK-8903 alleviated chilling injury at the site of cell membrane. Because of the decreased activity of catalase and peroxidase during chilling, $\mathrm{H}_{2} \mathrm{O}_{2}$ content increased (Fig. 5). Through a series of reactions, as discussed above, the plants eventually accumulated MDA (Fig. 6).

SOD, POD, and CAT activities suggest that GLK-8903 treatment did not enhance the scavenging ability of these enzymes at either 25 or 4C. In fact, GLK-8903 treatment significantly reduced the activity of CAT compared to that of the untreated controls (Fig. 4). GLK-8903 per se and the total lipids extracted from GLK-8903-treated plants are capable of reducing the $\mathrm{Fe}^{+2}$-catalyzed linoleic acid oxidation. The lower MDA content observed in the chilled and treated plants compared to controls seemed to be a result of the prevention of the fatty acid peroxidation in membrane lipids by GLK-8903.

It is known that chemical agents such as ABA analogues (Flores et al., 1989) and mefluidide (Zhang et al., 1986), which increase in endogenous free proline or free ABA content, improve a plant's chilling tolerance. Bean plants treated with GLK-8903 showed no difference compared with the control in free proline (Flores-Nimedez, et al., 1993) and free ABA content (data not shown) at either 25 or $5 \mathrm{C}$. It is unlikely that reduced chilling injury in bean plants by GLK-8903 is via the improved tolerance. There is the possibility that GLK-8903, like the Chinese herb medicine anisodamine, which has a polyheterocyclic structure with hydroxyl groups and which can reduce the membrane perturbation to relieve pain from sickness (Wang et al., 1983), may interact with the polar heads of the fatty acids in membrane lipids so that the physical state of the membrane is stabilized. During chilling, bean plasma membrane ATPase activity was significantly reduced, but the reduction in treated plants was much less than in the control (Flores-Nimedez et al., 1993). The plasma membrane permeability coefficient to urea was relatively stable in treated plants during chilling compared to the controls (Flores-Nimedez et al., 1993). GLK-8903 may substitute for unsaturated fatty acids in the membrane lipids as an $\mathrm{H}$ donor in direct reaction with the free radicals and, thus, prevent chilling injury by avoiding membrane lipid peroxidation. More evidence on the alterations of unsaturated fatty acids in vitro and in vivo with the GLK-8903 treatment is needed to support the proposed working model.

\section{Literature Cited}

Aebi, H.E. 1983. Catalase, p. 273-286. In: H.U. Bergmeyer, J. Bergmeyer, and M. Grabl (eds.). Methods of enzymatic analysis. vol. 3. Verlag Chemic, Weinheim.

Asada, K. and M. Takahashi. 1987. Production and scavenging of active oxygen in photosynthesis, p. 227-287. In: D.J. Kyle, C.B. Osmond, and C.J. Arntzen (eds.). Photoinhibition. Elsevier, Amsterdam.

Beauchamp, C. and I. Fridovich. 1971. Superoxide dismutase. Improved assays and an assay applicable to acrylamide gel. Anal. Biochem. 44:276-287.

Cadenas, E. 1989. Biochemistry of oxygen toxicity. Annu. Rev. Biochem. 58:79-110.

Chen, Y.E. and B.D. Patterson. 1988. The effect of chilling temperature on the level of superoxide dismutase, catalase and hydrogen peroxide in some plant leaves. Acta Phytophysiol. Sinica 14:323-328.

Clare, D.A., H.D. Rabinowitch, and I. Fridovich. 1984. Superoxide dismutase and chilling injury in Chlorella ellisoidea. Arch. Biochem. Biophys. 231:158-163.

Dhindsa, R.S., P.L. Plumb-Dhindsa, and D.M. Reid. 1982. Leaf senescence and lipid peroxidation: Effects of some phytohormones, and scavengers of free radicals and singlet oxygen. Physiol. Plant. 56:454457.
Elstner, E.F. 1982. Oxygen activation and oxygen toxicity. Annu. Rev. Plant Physiol. 33:73-96.

Flores, A., A. Grau, F. Laurich, and K. Dorffling. 1989. Effects of new terpenoid analogues of abscisic acid on chilling and freezing resistance. J. Plant Physiol. 132:362-369.

Flores-Nimedez, A.A., P.H. Li, and C.C. Shin. 1993. Amelioration of chilling injury in Phaseolus vulgaris L. by GLK-8903. J. Amer. Soc. Hort. Sci. 118:825-830.

Gross, G.G., C. Janse, and E.F. Elstner. 1977. Involvement of malate, monophenol and the superoxide radical in hydrogen peroxide formation by isolated cell walls from horseradish (Armoracia lapathifolia Gilib). Planta 136:271-176.

Halliwell, B. 1987. Oxidative damage, lipid peroxidation and antioxidant protection in chloroplast. Chem. Phys. Lipids 44:327-340.

Jahnke, L.S., M.R. Hull, and S.P. Long. 1991. Chilling stress and oxygen metabolizing enzymes in Zea mays and Zea diploperennis. Plant Cell Environ. 14:97-104.

Kaniuga, Z., B. Sochanowicz, J. Zabek, and K. Krzystyniak. 1978. Photosynthetic apparatus in chilling-sensitive plants. I. Reactivation of Hill reaction activity inhibited in the cold and dark storage of detached leaves and intact plants. Planta 140:121-128.

Kendall, E.J. and B.D. McKersie. 1989. Free radical and freezing injury to cell membranes of winter wheat. Physiol. Plant. 76:86-94.

Layne, E. 1957. Spectrophotometric method for measuring proteins, p. 447-454. In: S.P. Colowick and N.W. Kaplan (eds.). Methods in enzymology. vol 3. Academic Press, New York.

Levitt, J. 1980. Responses of plants to environmental stresses. 2nd ed. vol. 1. Academic Press, New York.

Liu, H.X., S.X. Zeng, Y.R. Wang, P. Li, D.F. Chen, and J.Y. Guo. 1985. The effect of low temperature on superoxide dismutase in various organelles of cucumber seedling cotyledon with different cold tolerance. Acta Phytophysiol. Sinica 11:48-57.

Michalski, W.P. and Z. Kaniuga. 1981. Photosynthetic apparatus of chilling-sensitive plants. X. Relationship between superoxide dismutase activity and photoperoxidation of chloroplast lipids. Biochim. Biophys. Acta 637:159-167.

Michalski, W.P. and Z. Kaniuga. 1982. Photosynthetic apparatus of chilling-sensitive plants. XI. Reversibility by light of cold- and darkinduced inactivation of cyanide-sensitive superoxide dismutase activity in tomato leaf chloroplast. Biochim. Biophys. Acta. 680:250-257.

Oberley, L. and D. Spitz. 1985. Nitroblue tetrazolium, p. 217-220. In: R.A. Greenwald (ed.). Handbook of methods for oxygen radical research. CRC Press, Boca Raton, Fla.

Ohkawa, H., N. Ohishi, and K. Yaji. 1979. Assays for lipid peroxides in animal tissue by thiobarbituric acid reaction. Anal. Biochem. 95:351358.

Patterson, B.D., E.A. MacRae, and I.B. Ferguson. 1984. Estimation of hydrogen peroxide in plant extracts using titanium(IV). Anal. Biochem. 112:247-273.

Porter, N.A. and D.G. Wujek. 1988. The autooxidation of polyunsaturated lipids, p. 55-80. In: A Quintanilha (ed.). Reactive oxygen species in chemistry, biology and medicine. Plenum Press, New York.

Powles, S.B. 1984. Photooxidation and photoinhibition in higher plants. Annu. Rev. Plant Physiol. 35:15-43.

Pryor, W.A. 1978. Formation of free-radicals and the consequences of their reactions in vivo. Photochem. Photobiol. 28:787-793.

Putter, J., 1974. Peroxidase, p. 685-689. In: H.U. Bergmeyer (ed.). Methods of enzymatic analysis. vol. 2. Academic Press, New York.

Senaratna J., B.D. McKersie, and R.H. Stinson. 1985. Antioxidant levels in germinating soybean seed axes in related to free radical and dehydration tolerance. Plant Physiol. 78:168-171.

Slater, T.F. and K.H. Cheeseman. 1988. Free radical mechanisms of tissue injury and mechanisms of protection, p. 1-14. In: A. Quintanilha (ed.). Reactive oxygen species in chemistry, biology and medicine. Plenum press, New York.

Symons, A.M., E.J. Dowling, and D.V. Park. 1988. Lipid peroxidation, free radicals and experimental inflammation, p. 87-995. In: M.G. Simic, K.A. Taylor, J.A. Ward, and V.S. Clemens (eds.). Oxygen radicals in biology and medicine. Plenum Press, New York. 
Takahama, U. and M. Nishimura. 1975. Formation of single molecular oxygen in illuminated chloroplast: Effect on photoinactivation and lipid peroxidation. Plant Cell Physiol. 16:737-748.

Wang, S.M., F. Huang, Y.Z. Fu, Z.L. Zhang, and R.J. Dong. 1983. Study of the effect of herb medicines on fluidity of phospholipid liposomes by differential scanning calorimeter. Sci. Bul. Sinica (1):60-62.

Wise, R.R. and A.W. Naylor. 1987. Chilling-enhanced photooxidation:
The peroxidative destruction of lipids during chilling injury to photosynthesis and ultrastructure. Plant Physiol. 83:272-277.

Xin, Z.G. and P.H. Li. 1992. Abscisic acid-induced chilling tolerance in maize suspension-cultured cells. Plant Physiol. 99:707-711.

Zhang, C.L., P.H. Li, and M.L. Brenner. 1986. Relationship between mefluidide treatment and abscisic acid metabolism in chilled corn leaves. Plant Physiol. 81:699-701. 